\title{
Godoy \& Godoy Compression Sleeve in the Treatment of Arm Lymphedema: New Concepts for Materials
}

\author{
José Maria Pereira de Godoy ${ }^{*}$, Ana Carolina Pereira de Godoy ${ }^{2,3}$ and Maria de Fatima \\ Guerreiro Godoy ${ }^{1,3}$ \\ ${ }^{1}$ Departamento de Cardiologia e Cirurgia Cardiovascular; Faculdade de Medicina de São José do Rio Preto; São \\ Jose do Rio Preto - SP - Brasil. ${ }^{2}$ Faculdade de Medicina do ABC; São Paulo - SP - Brasil. ${ }^{3}$ Grupo de Pesquisa \\ Clínica Godoy; São José do Rio Preto - SP - Brasil
}

\begin{abstract}
The aim of this work was to study on a new low-elastic textile that fulfilled the criteria of fabrics for the manufacture of compression garments to treat lymphedema. The evolution of Godoy \& Godoy compression sleeves was performed by following the patients treated for arm lymphedema. Sixty-six patients with ages ranging from 35 to 83 years and a mean of 58.8 years were included in this study. Diagnosis, by the clinical evaluation confirmed by the volumetry, was defined as a volume difference of more than $200 \mathrm{~mL}$ between the arms. All the participants were submitted to treatment sessions once, or two times weekly in an outpatient setting. The material used for the compression sleeve in this study was commercialized in Brazil under the name of Gorgurão ${ }^{\circledR}$. When high alterations in the pattern of sleeves were made, the patients were monitored by weekly volumetric assessments. The criterion to maintain the modifications in the design was that the hand did not present with edema. By the end of the study, the design of the sleeve was changed so as not to use compression therapy of the hands in $81.8 \%$ of the cases; $12.2 \%$ continued with compression of the hand, 3.0\% stopped using compression completely and 3.0\% used only a glove. Thus, Godoy \& Godoy compression sleeves could be an efficient option for compression in the treatment of arm lymphedema as they provided better independence in day-to-day activities.
\end{abstract}

Key words: Lymphedema, compression sleeves, day-to-day activities

\section{INTRODUCTION}

Despite of the high incidence of breast cancer, the survival of women treated in the early stages of the disease has increased (INCA 2013). One of the complications of breast cancer treatment is lymphedema with an incidence from 5 to $56 \%$ (Hayes et al. 2008; Shimony et al. 2008), and thus this disease should be treated as a public health problem.

Lymphedema after breast cancer treatment causes major changes in the functionality of the arm and is associated with social and psychological alterations (McWayne et al. 2005; ThomasMaclean et al. 2008). There is no consensus on a single therapy to treat lymphedema but a combination of techniques is recommended (de Godoy et al. 2010). These techniques include manual lymph drainage (Földi et al. 2003), myolymphokinetic exercises and activities (Johansson et al. 2005; Markes et al. 2006; Godoy MFG et al. 2008), compression garments and bandages (Partsch et al. 2008), daily hygienic care (Pereira de Godoy et al. 2008), counseling on diet (Shaw et al. 2007), psychological support (Heiney et al. 2007; Pereira de Godoy et al. 2009),

*Author for correspondence: godoyjmp@ riopreto.com.br 
lymphokinetic drugs (Badger et al. 2004), cervical stimulation (Godoy et al. 2009) and mechanical lymph drainage (Bordin et al. 2009).

Compression mechanisms are one of the main forms of therapy to reduce the volume of edema. A study comparing multicomponent and twocomponent inelastic bandages reported good results using multicomponent bandaging (Damstra et al. 2009; Kang et al. 2012). However, the twocomponent system is considered a suitable alternative (Lamprou et al. 2011). Inelastic compression, such as bandaging of the arms, is recommended but this technique requires much training. One problem of bandages is that the method is often not used, or used incorrectly due to the lack of trained professionals. Elastic materials are employed to maintain the results of treatment (Stout et al. 2012; Partsch 2012; Flour et al. 2013). Thus, studies on new materials that may reduce this problem are necessary.

The aim of this study was to study a new material that not only met the criteria of low elasticity for the compression therapy used in the treatment of lymphedema but also provided better independence for the patients.

\section{MATERIALS AND METHODS}

A quasi randomized prospective study was performed to evaluate the evolution of Godoy \& Godoy compression sleeves during the follow up of the patients treated for arm lymphedema. The study, performed between September 2004 and December 2009 in the Godoy Clinic in Sao Jose do Rio Preto, Brazil, involved 66 patients with breast cancer-related lymphedema. The patients' ages ranged from 35 to 83 years with a mean of 58.8 years. Diagnosis of lymphedema, characterized by a difference of more than $200 \mathrm{~mL}$ volume between the arms, was made by clinical evaluation and water displacement volumetry. Enrolment of patients was by order of arrival at the clinic. Patients in end-stage disease and those who did not accept to participate were excluded. All the participants were submitted to the treatment once, or two times a week in an outpatient program, which included manual lymph drainage (Földi et al. 2003), mechanical lymph drainage using the Godoy \& Godoy technique (Bordin et al. 2009), myolymphokinetic exercises and activities (Godoy et al. 2008) and a compression sleeve made of a cotton-polyester textile called Gorgurão ${ }^{\circledR}$ (de
Godoy et al. 2010). Gorgurão ${ }^{\circledR}$, known as grosgrain in English, is a ribbed textile made of $60 \%$ polyester and $40 \%$ cotton: this gives it the characteristics of low elasticity and extensibility $(<$ 50) across the textile and elasticity along its length as illustrated in Figure 1.

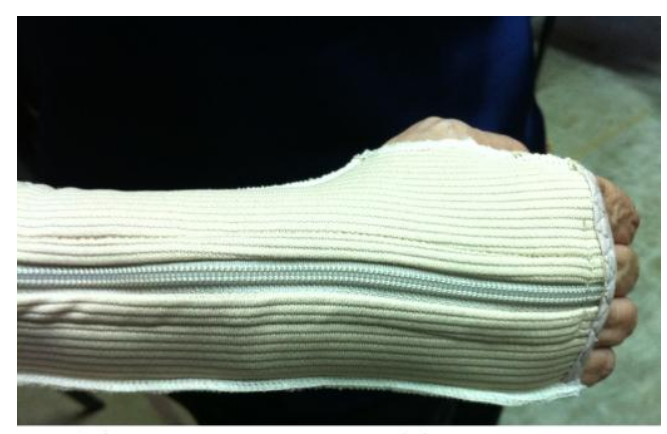

Figure 1 - External lengthwise seam: note that the ribs of the textile run along the arm.

Each patient was assessed by perimetry before making the garment. As the treatment evolved, changes were made in the design of the compression sleeves with these modifications being evaluated during the follow up of the patients. The design always took into account the patient's tolerance to the treatment, ease to dress and undress the garment, price, arm size and independence in respect to daily activities. The sleeves were made of this textile and either $3-\mathrm{cm}$ Velcro, or a zipper (18-20 cm in length) following some basic rules such as the direction of the sewing. Velcro was used at the start of treatment when the volume of edema was higher (Fig. 2A) because reductions in circumference of two to three centimeters were possible within one week, and thus the sleeve needed to be constantly adjusted. In the second phase, the reductions were smaller and so a zipper was used as it was easier to dress and undress the sleeve; even so frequent adjustments were still required (Fig. 2B).

The first design included part of the hand (Fig. 3A) but later, the sleeve was made without compression of the hand (Fig. 3B). During this change in the design, volumetric measurements were taken weekly to assess the effect on the lymphedema. The criteria used to accept the changes in design were that the reduction in volume was not lost and clinical observations that the hand did not present with edema. The criteria used to change back to a previous design were if the patient started having edema of the hand, or the volume of the limb increased. All the patients 
were informed about the objectives of the study and, on acceptance to participate, signed written informed consent forms.

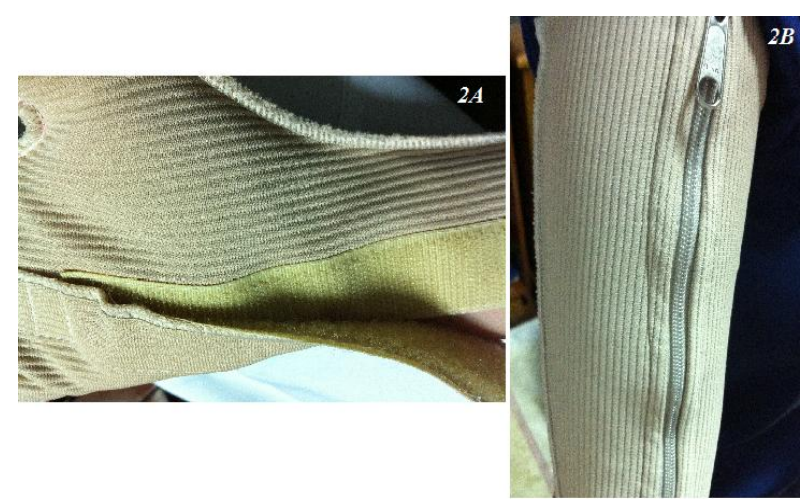

Figure 2 - A and B closure using Velcro or a zipper.

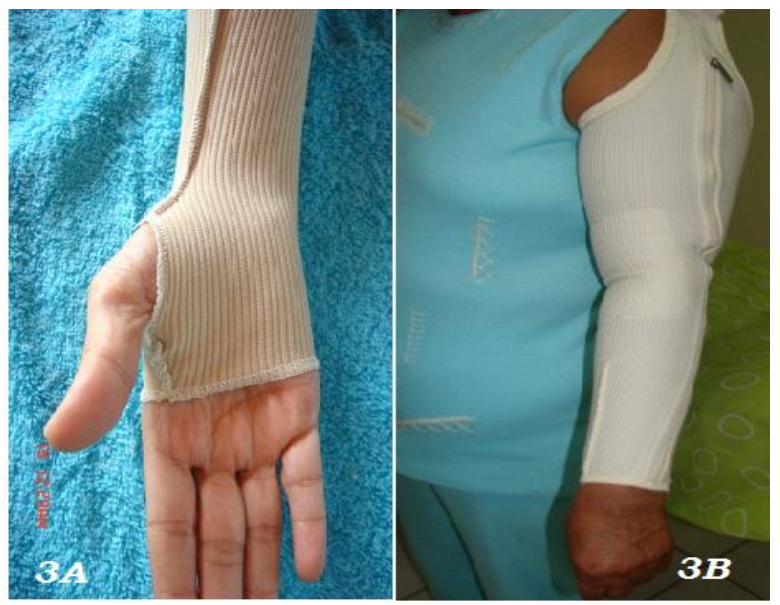

Figure 3 - (A ) compression of the hand and (B) no compression of the hand.

\section{RESULTS}

The sleeves of all the patients were adapted to their personal needs; a zipper was used for all the patients after the initial phase of treatment. By the end of the study, the design of the sleeve, so as not to use compression therapy of the hands, had changed for $81.8 \%$ of the patients; $12.2 \%$ continued with compression of the hand, $3.0 \%$ stopped to use compression completely and $3.0 \%$ used only a glove. The time necessary to dress, the sleeve varied between one and five minutes depending on the ability of the given patient; in some cases relatives were available to assist by adjusting the sleeve. All the patients who experienced modifications of the sleeve reported greater independence in day-to-day activities.

\section{DISCUSSION}

The low-elastic cotton-polyester sleeve created by Godoy \& Godoy is a new concept in the compression therapy of lymphedematous arms. The development of different designs aimed to give more independence to the patients in daily activities by simplifying the dressing and undressing of the sleeves. All the patients had the compression sleeves individually adjusted depending on their tolerance. Descriptions of the characteristics of this material were not found in the literature, thus this was a new treatment option for lymphedema of the upper limbs. The most important requirement is inelasticity across the textile; this fabric can be used to replace the bandages as it exerts working and resting pressures (Tereza et al. 2011). This made the compression sleeve effective to reduce the volume of edema when associated with myolymphokinetic activities (Godoy et al. 2008).

Functionally, grosgrain (gorgurão) causes a resting pressure similar to an elastic compression mechanism but allows a good fit on the arm. At the same time, this fabric causes a working pressure similar to inelastic, or low-stretch materials. Hence, this material has the traits of both elastic and inelastic textiles without using spandex (elastane) as one component. Bandages have resting and working pressures similar to this material. The difference between the conventional compression materials for lymphedema treatment and grosgrain is that the latter causes significant resting and working pressures. The resting pressure is the constant pressure on the arm, whether in the movement or not, which depends on the adjustment of the sleeve. Working pressures on the other hand are the pressure variations linked to muscle activity. The working pressures depend on the restraint imposed by the sleeves with pressure being caused by the muscle activity during the movement. The grosgrain sleeve proved to be efficient in the treatment of lymphedema (Godoy et al. 2008).

The main difference of these sleeves is related to the compression of the hands. This cottonpolyester textile allows the patient to work with proximal compression, that is, compression of the forearm and upper arm; this feature gives more independence in daily activities as, for example, it is possible to do tasks involving water without having to take off the sleeve. This change runs counter to prevailing concepts on compression of 
the arms that state that compression of the hand is necessary. Another aspect is that this design allows patients to wear long-sleeved shirts that hide the compression garment during leisure activities; this is very important for some patients.

The clinical evaluation of hand edema along with the changes in size after modifying the design of the sleeve was decisive in the evolution of this compression garment. The volume of the limb was monitored after altering the design using careful scientific evaluations in order to identify, which patients might benefit. At the end of the study, only two patients used gloves to control edema of the hands. These sleeves required constant adjustments because the reduction of volume is continuous until the size of the limb was close to normal; without adjustments the effect of the compression garment was lost.

It is essential to have a seamstress, or company to make the garments individually tailored to the size of each arm. The low cost and good tolerance at all social levels could make this sleeve an important humanitarian option in the treatment of lymphedema in endemic and needy regions.

\section{CONCLUSION}

The Godoy \& Godoy compression sleeve could be an option in the treatment of arm lymphedema, allowing better independence in daily activities. Associated to guidance on day-to-day conditions, it was efficient in the treatment of lymphedema.

\section{REFERENCES}

Badger C, Seers K, Preston N, Mortimer P. Antibiotics / anti-inflammatories for reducing acute inflammatory episodes in lymphoedema of the limbs. Cochrane Database Syst Rev. 2004;(2):CD003143.

Bordin HA, Godoy MdF, de Godoy JMP. Mechanical lymphatic drainage in the treatment of arm lymphedema. Indian J Cancer. 2009;46(4):337-339.

Damstra RJ, Partsch H. Compression therapy in breast cancer-related lymphedema: A randomized, controlled comparative study of relation between volume and interface pressure changes. $J$ Vasc Surg. 2009 ; 49(5):1256-1263.

de Godoy JMP, de Godoy MdFG. Godoy \& Godoy technique in the treatment of lymphedema for underprivileged populations. Int J Med Sci. 2010; 7(2):6871.
Flour M, Clark M, Partsch H, Mosti G, Uhl JF, Chauveau M, Cros F, Gelade P, Bender D, Andriessen A, Schuren J, Cornu-Thenard A, Arkans E, Milic D, Benigni JP, Damstra R, Szolnoky G, Schingale F. Dogmas and controversies in compression therapy: report of an International Compression Club (ICC) meeting, Brussels, May 2011. Int Wound J. 2013 ;10(5):516526.

Foldi M, Foldi E, Kubik S. Lymphostatic Disease. In Textbook of Lymphology. For Physicians and Lymphedema Therapists. Munich: Urban \& Fischer. 2003 p. 280

Godoy JMP, Godoy MFG, Braile DM, Testoni B,Sanches RG. Dynamic Evaluation of working pressures with 'gorgurao' sleeves used in the treatment of lymphedema of the arm. J Phlebol and Lymphol. 2008; 1:5-7.

Godoy JM, Godoy MdF, Meza MC. Godoy \& Godoy technique of cervical stimulation in the reduction of edema of the face after cancer treatment. QJM. 2008;101(4):325-326.

Godoy MFG, Godoy JMP, Braile DM. Pilot study with Myolymphokinetic activities in the treatment of lymphedema after breast cancer. Indian J Physiother Occup Ther. 2008; 2 (3):17-19.

Hayes SC, Janda M, Cornish B, Battistutta D, Newman B. Lymphedema after breast cancer: incidence, risk factors, and effect on upper body function. J Clin Oncol. 2008;26(21):3536-3544.

Heiney SP, McWayne J, Cunningham JE, Hazlett LJ, Parrish RS, Bryant LH, Vitoc C, Jansen K. Quality of life and lymphedema following breast cancer. Lymphology. 2007;40(4):177-184.

INCA (Instituto Nacional do Câncer) 2013 - Incidência do Câncer no Brasil. Available at: www.inca.gov.br/estimativa/2013.

Johansson K, Tibe K, Weibull A, Newton RC. Low intensity resistance exercise for breast cancer patients with arm lymphedema with or without compression sleeve. Lymphology. 2005;38(4):167-180.

Kang Y, Jang DH, Jeon JY, Lee SJ, Jeong SY, Shin DI, Kim HJ. Pressure monitoring of multilayer inelastic bandaging and the effect of padding in breast cancer-relatedlymphedema patients. Am J Phys Med Rehabil. 2012 ;91(9):768-73. doi: 10.1097/ PHM.0b013e3182643c36.

Lamprou DA, Damstra RJ, Partsch H. Prospective, randomized, controlled trial comparing a new twocomponent compression system with inelastic multicomponent compression bandages in the treatment of leg lymphedema. Dermatol Surg. 2011 ;37(7):985-991.

Markes M, Brockow T, Resch Kl. Exercise for women receiving adjuvant therapy for breast cancer. Cochrane Database Syst Rev. 2006, 18(4):CD005001. 
McWayne J, Heiney SP. Psychological and social sequelae of secondary lymphedema: a review. Cancer. 2005;104(3):457-466.

Partsch H. Compression therapy: clinical and experimental evidence. Ann Vasc Dis. 2012;5(4):41622. doi: 10.3400/avd.ra.12.00068. Partsch H, Flour M, Smith PC; International Compression Club. Indications for compression therapy in venous and lymphatic disease consensus based on experimental data and scientific evidence. Under the auspices of the IUP. Int Angiol. 2008 ;27(3):193-219.

Pereira de Godoy JMP, da Silva SH, Guerreiro Godoy $\mathrm{MdF}$. Interference of the surgical treatment of breast cancer on personal hygiene. Breast J. 2008;14(6):607.

Pereira de Godoy JM, Da Silva SH, De Fátima Guerreiro Godoy M. Mechanisms used to face difficulties encountered following surgical treatment for breast cancer. Afr $J$ Psychiatry (Johannesbg). 2009;12(1):75-76.

Shaw C, Mortimer P, Judd PA. A randomized controlled trial of weight reduction as a treatment for breast cancer-related lymphedema. Cancer 2007;110(8):1868-187.
Shimony A, Tidhar D, Geffen DB. Cancer-related lymphedema in Israel. Harefuah. 2008;147(7):624627.

Stout N, Partsch H, Szolnoky G, Forner-Cordero I, Mosti G, Mortimer P, Flour M, Damstra R, Piller N, Geyer MJ, Benigni JP, Moffat C, Cornu-Thenard A, Schingale F, Clark M, Chauveau M. Chronic edema of the lower extremities: international consensus recommendations for compression therapy clinical research trials. Int Angiol. 2012 ;31(4):316329.

Thomas-Maclean RL, Hack T, Kwan W, Towers A, Miedema B, Tilley A. Arm morbidity and disability after breast cancer: new directions for care. Oncol Nurs Forum. 2008 ;35(1):65-71.
Received: May 17, 2015; Accepted: June 08, 2015. 